\title{
Dermatoses Específicas da Gravidez
}

\author{
Specific Dermatoses of Pregnancy
}

Vera TEIXEIRA ${ }^{1}$, Inês COUTINHO ${ }^{1}$, Rita GAMEIRO ${ }^{1}$, Ricardo VIEIRA ${ }^{1}$, Margarida GONÇALO ${ }^{1}$

Acta Med Port 2013 Sep-Oct;26(5):593-600

RESUMO

Durante a gravidez ocorrem alterações imunológicas, metabólicas, hormonais e vasculares que podem causar alterações cutâneas específicas. A nomenclatura e classificação das dermatoses específicas da gravidez têm sofrido alterações ao longo dos anos, em parte devido aos avanços na descoberta da patogénese destas dermatoses. São actualmente consideradas dermatoses específicas da gravidez: penfigóide gestacional, erupção polimorfa da gravidez, colestase intra-hepática da gravidez e erupção atópica da gravidez. O diagnóstico atempado e tratamento direcionado são essenciais para prevenir complicações que, apesar de raras, podem estar associadas a significativa comorbilidade materno-fetal.

Palavras-chave: Colestase Intra-Hepática; Complicações na Gravidez; Dermatite Atópica; Doenças da Pele; Penfigóide Gestacional; Prurido.

\section{ABSTRACT}

During pregnancy immunological, metabolic, hormonal and vascular changes occur, and can cause specific skin diseases. The specific dermatoses of pregnancy have undergone numerous changes in nomenclature and classification, partly due to advances in the knowledge of the pathogenesis of these skin diseases. Currently the following diseases are considered specific dermatoses of pregnancy: pemphigoid gestations, polymorphic eruption of pregnancy, intrahepatic cholestasis of pregnancy and atopic eruption of pregnancy. Timely diagnosis and specific and safe treatment are essential to prevent complications which, although rare, may be associated with significant maternal-fetal comorbidity.

Keywords: Cholestasis, Intrahepatic; Dermatitis, Atopic; Pemphigoid Gestationis; Pregnancy Complications; Pruritus; Skin Diseases.

\section{INTRODUÇÃO}

Durante a gravidez ocorrem alterações imunológicas, metabólicas, hormonais e vasculares que podem ser responsáveis por alterações cutâneas fisiológicas ou patológicas. De um modo geral, as modificações cutâneas da gravidez podem classificar-se em três grupos principais: fisiológicas, dermatoses e tumores cutâneos afectados pela gravidez e dermatoses específicas da gravidez (DEG). A classificação e nomenclatura das dermatoses da gravidez têm sido controversas ao longo dos anos.

A classificação tradicional das DEG inclui o penfigóide gestacional, a erupção polimorfa da gravidez, o prurigo da gravidez e as foliculites pruriginosas da gravidez (Tabela 1). Em 2006, Ambros-Rudolph et al propuseram uma nova classificação das DEG, baseada na observação de 505 grávidas com alterações cutâneas. ${ }^{1}$ Assim, além do penfigóide gestacional e da erupção polimorfa da gravidez, incluem a colestase intra-hepática da gravidez e o conceito de 'erupção atópica da gravidez'. Este último engloba eczema atópico da gravidez, prurigo da gravidez e foliculites pruriginosas da gravidez. ${ }^{1}$

Classicamente, a erupção polimorfa da gravidez era considerada a DEG mais frequente. Contudo, desde a introdução do termo erupção atópica da gravidez, esta representa cerca de $50 \%$ de todos os casos. ${ }^{1}$

As características clínicas, em particular o timing de início, morfologia e localização das lesões são dados essen- ciais para o diagnóstico, o qual deve ser apoiado no estudo histopatológico e em particular nos achados específicos da imunofluorescência directa e resultados laboratoriais, respectivamente no penfigóide gestacional e colestase intra-hepática da gravidez.

Esta revisão foca-se nas dermatoses específicas da gravidez, discutindo em detalhe o diagnóstico e correcta classificação, essenciais para o tratamento adequado.

\section{PENFIGÓIDE GESTATIONAL [sin: Herpes gestationis]}

Epidemiologia e Etiopatogénese - O penfigóide gestacional (PG), também conhecido como herpes gestationis, é uma dermatose bolhosa rara, cuja prevalência varia entre 1:7 000 e 1:50 000. É de etiologia autoimune e do ponto de vista imunopatológico está relacionado com o penfigóide bolhoso. Ocorre produção de autoanticorpos (sobretudo IgG1, conhecido como factor herpes gestationis), que se ligam ao antigénio $180 \mathrm{kDa}$ (BPAg2) dos hemidesmosomas da membrana basal. Posteriormente é activada a via clássica do complemento, com lesão a nível da junção dermo-epidérmica e formação de bolha subepidérmica. ${ }^{2}$ Curiosamente, o local primário de autoimunidade parece ser a placenta, ou seja, os autoanticorpos não se ligam apenas à membrana basal da epiderme, mas também ao epitélio coriónico e amniótico, ambos de origem ectodérmica. A explicação poderá ser uma resposta imunológica contra a

1. Serviço de Dermatologia e Venereologia. Centro Hospitalar da Universidade de Coimbra. Coimbra. Portugal.

Recebido: 24 de Fevereiro de 2013 - Aceite: 21 de Julho de 2013 | Copyright $\odot$ Ordem dos Médicos 2013 
Tabela 1 - Classificações tradicional e recente das dermatoses específicas da gravidez.

\begin{tabular}{l}
\hline Dermatoses específicas da gravidez - classificação tradicional \\
\hline Penfigóide gestacional \\
Erupção polimorfa da gravidez \\
Prurigo da gravidez \\
Foliculites pruriginosas da gravidez \\
\hline Dermatoses específicas da gravidez - classificação recente \\
\hline Penfigóide gestacional \\
Erupção polimorfa da gravidez \\
Erupção atópica da gravidez* (controverso) \\
Colestase intra-hepática da gravidez
\end{tabular}

Erupção atópica da gravidez inclui eczema atópico da gravidez, prurigo da gravidez e foliculites pruriginosas da gravidez.

expressão aberrante de moléculas MHC classe II (provavelmente de origem paterna) na placenta e posteriormente, reacção cruzada com antigénios cutâneos. A susceptibilidade genética é evidenciada pela associação dos antigénios HLA-DR3 (em 60-80\% das doentes), HLA-DR4 (50\%) ou ambas as formas (entre $40-50 \%$ ) e a detecção do alelo null de $\mathrm{C} 4$ (em $70 \%$ das doentes). ${ }^{2}$

Clínica e Diagnóstico - O PG inicia-se, habitualmente, no segundo ou terceiro trimestre da gravidez (em média às 21 semanas de gestação) ou no pós-parto imediato (em cerca de $15-25 \%$ dos casos). ${ }^{2}$ O prurido é o sintoma predominante. As lesões iniciam-se na região umbilical e periumbilical em cerca de metade dos casos e estendem-se a outras áreas do tronco e membros, frequentemente atingindo as palmas e plantas. São pápulas e placas urticariformes que adquirem aspecto policíclico ou em-alvo e que evoluem para uma erupção bolhosa generalizada, com bolhas tensas, sobre pele eritematosa ou sã (Fig. 1). A disposição em vesículas pode lembrar infecção herpética (daí a designação antiga de herpes gestationis), enquanto as bolhas tensas evocam penfigóide bolhoso ou lúpus boIhoso.

Os achados histológicos variam consoante o estadio e gravidade da doença. Na fase bolhosa é caraterística uma bolha subepidérmica, resultado da necrose focal dos ceratinocitos da camada basal devida aos autoanticorpos e a reacção inflamatória dermo-epidérmica habitualmente muito rica em eosinófilos, que podem preencher a bolha..$^{2,3}$ A imunofluorescência direta (IFD), considerada o gold-standard para o diagnóstico, tipicamente mostra deposição linear de C3 ao longo da membrana basal em todos os casos. ${ }^{4}$ Em $25-50 \%$ dos casos pode ocorrer também deposição de IgG. A IFD diferencia PG de erupção polimorfa da gravidez (IFD negativa nesta última), mesmo a posteriori,

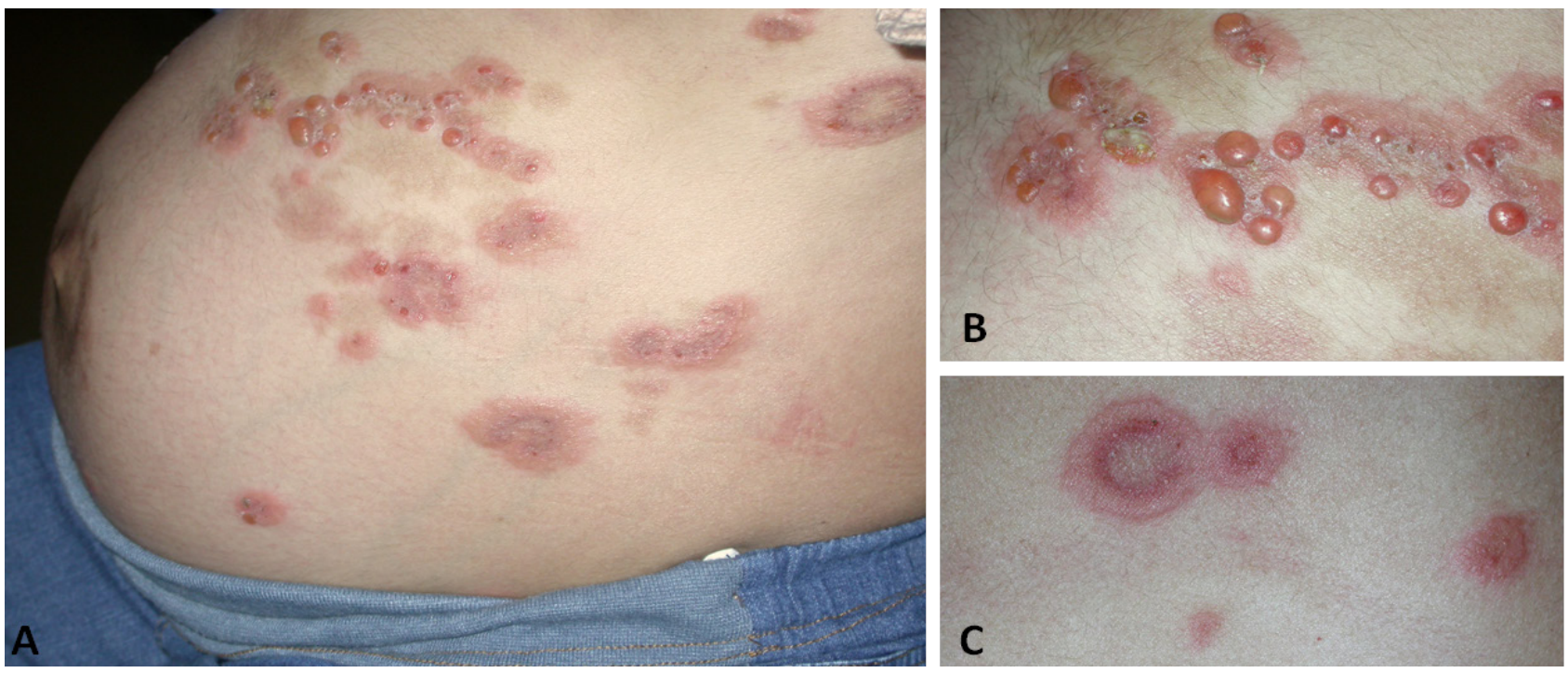

Figura 1 - Penfigóide gestacional. (A) placas urticariformes e bolhas tensas na região abdominal. (B) pormenor das bolhas tensas. (C) lesões em-alvo. 
pois a IFD pode permanecer positiva por seis meses a quatro anos após a remissão clínica.

Em regra, ocorre remissão do quadro no final da gravidez, seguido de agudização no período pós-parto, em $75 \%$ dos casos. Posteriormente, o quadro tem tendência a resolver espontaneamente em algumas semanas a meses. ${ }^{3}$

PG é, por definição, considerado crónico quando a dermatose tem duração superior a seis meses no período pós-parto, o que foi reportado em cerca de 20 casos..$^{5-8} \mathrm{O}$ PG pode recorrer em gestações subsequentes ou com a toma de anticonceptivos orais e menstruação. ${ }^{9} \mathrm{~A}$ recorrência tipicamente ocorre em dias a semanas após iniciar o anticonceptivo oral e desaparece após a sua suspensão. ${ }^{10}$ De referir ainda que a recorrência numa gestação seguinte é, habitualmente, mais precoce e mais grave. Raramente, têm sido reportadas skip pregnancies (cerca de $8 \%$ dos casos), ${ }^{3,9}$ facto atribuído à troca de parceiro ou expressão de antigénios HLA-DR idênticos pela mãe e feto. ${ }^{9}$

Tratamento - A corticoterapia oral é o tratamento de eleição do PG e a maioria das doentes melhora em alguns dias. Os dermocorticóides potentes podem ser úteis nas lesões urticariformes iniciais ou nas agudizações pré-menstruais. O tratamento com prednisona deve ser iniciado com doses baixas $(0,25-0,50 \mathrm{mg} / \mathrm{Kg} / \mathrm{dia})$ e aumentada até se obter resposta clínica. Em casos graves, podem ser necessárias doses mais elevadas,-até $3 \mathrm{mg} / \mathrm{Kg} / \mathrm{dia}$. Assim que a formação de bolhas novas tiver sido suprimida, a dose de prednisona deve ser lentamente diminuída ou mesmo descontinuada. Segundo alguns autores, a dose deverá ser novamente aumentada imediatamente após o parto, para prevenir a agudização da dermatose. ${ }^{11}$

No entanto, doses elevadas de corticóides podem representar um fator de risco para rutura prematura de membranas, parto pré-termo, atraso de crescimento intrauterino e efeitos laterais maternos. A prednisona é considerada relativamente segura durante a gravidez, mas outros corticoesteróides como a betametasona e a dexametasona que atravessam a placenta devem ser evitados, pois representam toxicidade adicional para o feto. ${ }^{2}$ Doses de prednisona até $20 \mathrm{mg} /$ dia são consideradas seguras para amamentação.

Tratamentos alternativos devem ser considerados no período pós-parto nos casos recalcitrantes ou crónicos devido aos efeitos adversos graves associados com o uso prolongado de corticóides. Algumas opções são a minociclina ou doxiciclina, assim como imunoglobulina endovenosa combinada com ciclosporina ou outros tratamentos imunossupressores. ${ }^{8,11}$

Complicações - Apesar de existir uma tendência para recém-nascidos (RN) com baixo peso e prematuridade (20\%), o PG não foi associado a maior mortalidade fetal ou do $\mathrm{RN} .{ }^{10}$ Os riscos fetais não diminuem com a instituição precoce do tratamento, e pensa-se estarem associados a um certo grau de insuficiência placentária. ${ }^{12}$ Huilaja et al sugeriram que os autoanticoporpos BP-180 podem induzir microseparação epitelio-estromal na placenta, o que pode provocar alguma falência funcional da placenta e explicar as complicações fetais, nomeadamente o baixo peso ob- servado nos RN. ${ }^{13}$ A passagem de anticorpos através da placenta pode causar lesões de PG no RN (até cerca de $10 \%$ ), mas estas desaparecem sem deixar sequelas. ${ }^{14}$

As doentes têm um risco aumentado de doença de Graves $(10 \%$ das doentes comparado com $0,4 \%$ dos controlos), que não se desenvolve simultaneamente com o PG. ${ }^{10}$ Outros riscos maternos estão relacionados com efeitos colaterais dos fármacos usados.

\section{ERUPÇÃO POLIMORFA DA GRAVIDEZ [sin: Pápulas e placas urticariformes pruriginosas da gravidez] \\ Epidemiologia e Etiopatogénese - É uma das DEG} mais frequentes, atingindo entre 1:600 a 1:240 gestações. Atualmente tem sido preferida a designação de erupção polimorfa da gravidez, em substituição de pápulas e placas urticariformes pruriginosas da gravidez. De carácter benigno e autolimitado, esta dermatose ocorre sobretudo em primíparas (em $80 \%$ dos casos) e no terceiro trimestre da gravidez (em média às 35 semanas). ${ }^{15}$ Dura cerca de seis semanas, resolvendo espontaneamente, sendo a primeira semana o período mais sintomático. ${ }^{16}$

A etiopatogénese não está esclarecida. As teorias propostas focam-se na distensão abdominal, factores hormonais e imunológicos. A localização característica das lesões nas estrias abdominais e a associação com gestações gemelares, ${ }^{17}$ com aumento excessivo de peso na mãe e feto $^{18}$ e com a obesidade materna ${ }^{19}$ conduziram à hipótese de que a distensão rápida da parede abdominal nas primíparas durante a última fase da gravidez poderia causar dano no tecido conectivo das estrias, e assim causar uma reação inflamatória. ${ }^{18,20}$ No entanto, as associações com o excessivo peso materno e fetal têm sido questionadas. ${ }^{21,22}$ Também não há evidência científica de associação com fatores hormonais e imunológicos.

Clínica e Diagnóstico - Caracteristicamente, em cerca de dois terços dos casos surgem pápulas urticariformes muito pruriginosas nas estrias abdominais poupando a região periumbilical (em contraste com o penfigóide gestacional). ${ }^{17}$ Posteriormente podem coalescer em placas e estender-se à região proximal dos membros inferiores, membros superiores e outras partes do tronco. A face, pescoço, palmas e plantas estão, geralmente, poupados. A erupção pode tornar-se polimorfa, com vesículas (15\%), lesões em alvo $(5 \%)$ e lesões policíclicas $(5 \%) .{ }^{16}$ Escoriações e lesões eczematiformes (20\%) são frequentes na fase pré-resolutiva. A presença de lesões polimorfas pode aumentar com a duração da doença, tendo sido reportada a associação entre lesões não-urticariformes e duração da doença superior a seis meses. ${ }^{16}$

A histologia é inespecífica e varia consoante o estádio da dermatose. Nas lesões iniciais predomina edema da derme superior e infiltrado dérmico linfo-histiocitário com um número variável de eosinófilos. ${ }^{4}$ Por sua vez, as lesões mais antigas mostram alterações epidérmicas (espongiose, paraqueratose, acantose e exocitose). A infiltração eosinofílica pode ser marcada em até um terço dos casos, mas é menos intensa do que no PG. ${ }^{23}$ A IFD e outros testes se- 
rológicos para deteção de autoanticorpos circulantes são negativos.

Tratamento - A erupção polimorfa da gravidez de intensidade ligeira a moderada pode ser tratada sintomaticamente com medidas gerais (emolientes, compressas húmidas na pele), antipruriginosos tópicos, dermocorticóides de potência baixa e anti-histamínicos orais.

A utilização de anti-histamínicos de primeira geração (p.e., hidroxizina, difenidramina) durante a gravidez não está associada a quaisquer riscos fetais, sendo considerados seguros. ${ }^{24}$ Muitas vezes, os anti-histamínicos de segunda geração (p.e., cetirizina, desloratadina e loratadina) são preferidos, uma vez que quase não atravessam a barreira hemato-encefálica e quase não causam sonolência. Apesar de existirem relativamente poucos estudos em relação ao uso dos anti-histamínicos de segunda geração durante a gravidez, não têm sido encontradas aumento da incidência de malformações fetais, mesmo com o uso durante o primeiro trimestre. ${ }^{25}$

Nos casos com prurido intenso ou quando a erupção se torna generalizada, pode considerar-se um ciclo curto de corticoterapia oral (prednisona ou prednisolona), bastante eficaz. O risco de insuficiência supra-renal fetal secundário ao ciclo curto de corticosteróides orais é considerado baixo, e evidenciado pelo facto de o gradiente materno-fetal de prednisolona ser 10:1.26

Complicações - A erupção polimorfa da gravidez é autolimitada na sua duração, não recorre nas gestações subsequentes e não acarreta qualquer risco para a mãe ou feto.

ERUPÇÃO ATÓPICA DA GRAVIDEZ [sin: Eczema na gravidez, Prurigo da gravidez, Prurigo gestationis, Foliculites pruriginosas da gravidez]

A erupção atópica da gravidez, conceito introduzido recentemente, é definida como exacerbação ou primeira manifestação de lesões eczematiformes ou papulosas em doentes com antecedentes de atopia, após exclusão de outras patologias. ${ }^{1}$ Como já referido, é responsável por cerca de $50 \%$ das dermatoses da gravidez e tem início precoce, antes do terceiro trimestre, em cerca de $75 \%$ dos casos. Tende a recorrer em gestações posteriores, dado o contexto de atopia. Pensa-se que esta dermatose seja desencadeada por alterações imunológicas específicas da gravidez: a diminuição da imunidade celular e da produção de citocinas Th1 (IL-2, interferão gama, IL-12) que contrasta com o domínio da imunidade humoral e aumento da secreção de citocinas Th2 (IL-4, IL-10). ${ }^{11}$

Esta nova classificação não é consensual, sendo controverso o agrupamento de entidades previamente individualizadas. ${ }^{27}$ Além disso, não está esclarecida a existência de associação entre atopia e prurigo da gravidez ou foliculites pruriginosas da gravidez. ${ }^{28}$

De seguida será abordado de forma mais pormenorizada o eczema atópico da gravidez, o prurigo da gravidez e as foliculites pruriginosas da gravidez.

\section{Eczema atópico}

Epidemiologia e Etiopatogénese - Nas doentes com antecedentes de eczema atópico, a evolução desta dermatose durante a gravidez é variável, embora ocorra agravamento em muitos casos (50\%). ${ }^{29} \mathrm{O}$ motivo desta tendência permanece por esclarecer. Alguns autores sugeriram que as alterações imunológicas próprias da gravidez com resposta Th2 predominante podem exacerbar o desequilíbrio já existente entre Th1/Th2 nas doentes com antecedentes de atopia. ${ }^{30}$ Assim, o aumento de IL-4 durante a gestação pode ser fundamental para a indução de produção de lgE, a qual pode assumir um papel importante no eczema atópico da gravidez.

A maioria das doentes $(80 \%)$ tem a primeira manifestação de atopia durante a gravidez ou após um longo período de remissão. Cerca de $20 \%$ das doentes têm exacerbação do eczema atópico pré-existente, com quadro clínico típico. ${ }^{11}$

Clínica e Diagnóstico - As manifestações clínicas do eczema atópico durante a gravidez são idênticas às da mulher não-grávida (Fig. 2). Dois terços dos casos manifestam-se com lesões disseminadas de eczema (erupção atópica da gravidez do tipo E), atingindo os locais típicos do eczema atópico (face, pescoço, pregas). Um terço das doentes tem apenas pápulas (erupção atópica da gravidez do tipo P). ${ }^{1}$ Existe risco de sobreinfecção bacteriana (sobretudo com Staphylococcos aureus) ou vírica (eczema herpeticum).

Tratamento - Os dermocorticóides são a primeira-linha de tratamento do eczema atópico, associados aos cuidados de hidratação cutânea. Os anti-histamínicos podem ser úteis para controlar o prurido. Em casos de eczema grave e resistente ao tratamento com dermocorticóides, pode ser instituído um ciclo curto de corticoterapia oral. Os inibidores tópicos da calcineurina (tacrolimus e pimecrolimus) estão contra-indicados. A fototerapia com UVB é um tratamento eficaz e seguro a ser ponderado como tratamento de segunda linha nos casos mais graves. Em relação aos fármacos sistémicos, a ciclosporina é a opção mais segura

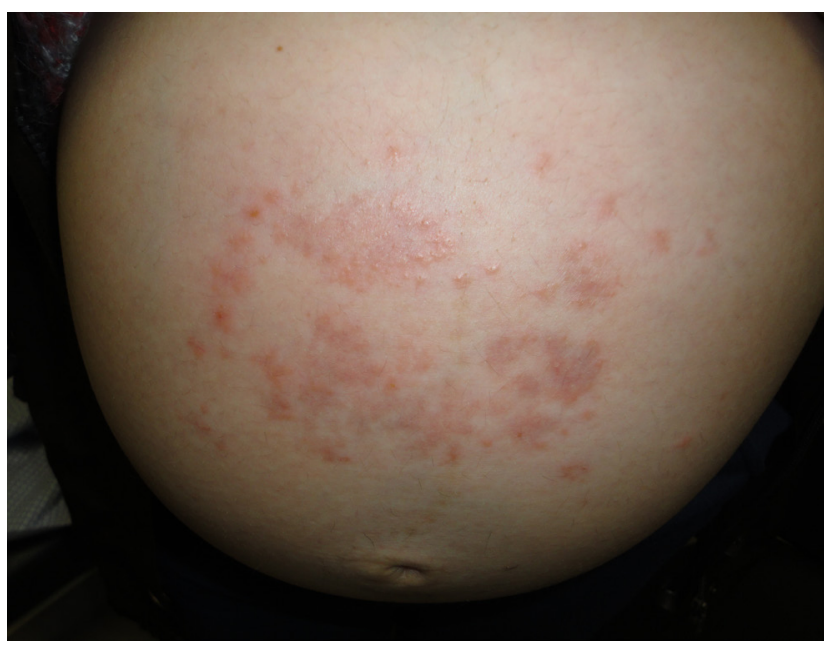

Figura 2 - Erupção atópica da gravidez: lesões eczematiformes no abdómen. 
durante a gravidez. Nos casos de sobreinfeção, a eritromicina ou penicilina são seguras durante a gravidez.

Complicações - Não existe evidência científica de riscos fetais associados ao eczema atópico da grávida.

\section{Prurigo da gravidez (PDG)}

Epidemiologia e Etiopatogénese - Esta dermatose afecta aproximadamente 1 em 300 gestações. Embora possa ocorrer em qualquer trimestre da gravidez, geralmente inicia-se às $25-30$ semanas de gestação e persiste até ao parto. ${ }^{4}$

A sua classificação e etiopatogénese não estão completamente definidas. Especula-se que o PDG e a colestase intra-hepática da gravidez estejam relacionados, pertencendo a níveis diferentes de gravidade da mesma doença. ${ }^{31}$ Outros autores sugerem uma associação do PDG com eczema atópico (história pessoal ou familiar), pelo que o PDG deverá ser incluído na erupção atópica da gravidez. ${ }^{1}$ Por outro lado, esta associação com a atopia nem sempre está presente, o que poderá reflectir a heterogeneidade dos mecanismos patogénicos do PDG.

Clínica e Diagnóstico - O prurigo da gravidez manifesta-se com papulovesículas agrupadas, intensamente pruriginosas sobre as superfícies extensoras dos membros e, ocasionalmente, no abdómen. Progressivamente, as lesões estendem-se ao tronco e restante tegumento. Escoriações e crostas são resultantes do prurido. ${ }^{10}$ Por vezes observam-se lesões indistinguíveis do prurigo nodular.

Esta condição resolve de forma espontânea no período pós-parto imediato, embora as lesões possam persistir por um período de três meses. Pode recorrer em gestações posteriores.

Os achados histológicos são inespecíficos e a IFD é negativa. Os níveis séricos de lgE estão aumentados em um terço das doentes. ${ }^{32}$

Tratamento - O tratamento sintomático para alívio do prurido inclui dermocorticóides de potência moderada e anti-histamínicos per os. Nos casos de prurido recalcitrante, pode ser administrado um ciclo curto de corticoterapia oral.

Complicações - PDG não está associado a riscos materno-fetais.

\section{Foliculites Pruriginosas da Gravidez (FPG)}

Epidemiologia e Etiopatogénese - Esta dermatose específica da gravidez é rara (menos de 30 casos relatados) e a etiopatogénese é desconhecida. Devido à semeIhança clínica com a acne induzida pelos corticóides, foi sugerido tratar-se de forma de acne hormonal, apesar de o doseamento das hormonas sexuais ser normal para a idade gestacional.

Clínica e Diagnóstico - Manifesta-se com pápulas eritematosas e pústulas foliculares pruriginosas, semelhantes a lesões de acne monomorfa, distribuídas pelo tronco. ${ }^{33}$ Resolve espontaneamente após o parto e pode recorrer em gestações posteriores.

O exame histopatológico mostra foliculite estéril, sem evidência de microrganismos. Acompanha-se de infiltrado inflamatório com linfócitos e neutrófilos. A IFD é negativa.

Tratamento - Tratamento tópico com peróxido de benzoilo e dermocorticóides de potência ligeira a moderada geralmente é suficiente. Em alguns a fototerapia UVB de banda estreita foi benéfica. ${ }^{34}$

Complicações - Sem riscos materno-fetais.

\section{COLESTASE INTRA-HEPÁTICA DA GRAVIDEZ [sin: prurigo gravidarum)}

Epidemiologia e Etiopatogénese - Durante anos esta entidade não foi incluída na classificação das dermatoses específicas da gravidez, uma vez que as lesões cutâneas observadas são secundárias ao prurido. Atualmente parece fazer sentido a sua inclusão, dado ser importante para o diagnóstico diferencial, pelos potenciais riscos fetais associados, que se podem agravar com atraso ou desconhecimento do diagnóstico.

A colestase intra-hepática da gravidez (CIHG) é uma patologia cuja incidência varia consoante a localização geográfica e etnia. É menos prevalente na Europa (0,1-2\% das gestações) e mais frequente no Chile (1,5-4\%), Bolívia e Escandinávia (1-2\%). ${ }^{35} \mathrm{Na}$ maioria das vezes $(70 \%)$ surge no terceiro trimestre da gravidez. ${ }^{35}$ Ocorre devido a discreta disfunção da secreção biliar intra-hepática, levando a acumulação de ácidos bilares no soro, responsáveis por prurido grave na doente e potenciais efeitos tóxicos no feto.

A etiopatogénese da CIHG é complexa e investigações recentes sugerem interação entre factores hormonais, imunológicos, genéticos, ambientais e alimentares. ${ }^{36}$ Os estrogénios interferem com a secreção de ácidos biliares. Recentemente, em famílias com casos de ClHG, foram encontradas mutações em genes que codificam proteínas transportadoras necessárias para a excreção biliar (p.e., gene $A B C B 4)$ o que corrobora a influência genética. ${ }^{37}$ Acrescenta-se o facto de este defeito genético não ter implicações clínicas com valores hormonais normais, apenas se manifestando com a elevação das concentrações hormonais (no fim da gravidez ou com a toma de anticonceptivos orais). Alguns autores discutem ainda o papel de factores ambientais e dietéticos, como a diminuição dos níveis séricos de selénio. ${ }^{38}$

A CIHG pode ser dividida em dois tipos: (a) colestase ictérica da gravidez, naquelas pacientes com hiperbilirrubinémia e, mais frequente: (b) prurigo gravídico, se existirem prurido e alterações bioquímicas, mas sem hiperbilirrubinémia ou icterícia.

Clínica e Diagnóstico - Caracteriza-se por prurido generalizado, com ou sem icterícia, ausência de lesões primárias, alterações bioquímicas consistentes com colestase hepática e resolução após o parto. Em cerca de metade dos casos pode recidivar nas gestações subsequentes. A progressão da doença não permite prever a gravidade da dermatose nas gestações seguintes. ${ }^{35}$

Geralmente o prurido antecede as alterações laboratoriais encontradas, agrava progressivamente com decorrer da gravidez e resolve em 48 horas após o parto. Atinge as palmas e plantas, estende-se às pernas e abdómen, 
podendo generalizar. Como já referido, não se observam outras lesões cutâneas além das marcas de coceira que podem variar desde simples escoriações até nódulos do tipo prurigo nodular. Em cerca de $15 \%$ dos casos pode surgir icterícia discreta 2-4 semanas após o início do prurido. Ao contrário do prurido, a icterícia não agrava com o decorrer da gravidez. ${ }^{35}$ Nos casos graves pode ainda ocorrer esteatorreia com má-absorção das vitaminas lipossolúveis, incluindo a vitamina $\mathrm{K}$, com potenciais complicações hemorrágicas, assim como colelitíase.

Os achados histológicos são inespecíficos e a IFD é negativa. Laboratorialmente, a CIHG está associada a elevação dos ácidos biliares no soro (em média, $1349 \mu \mathrm{g} / 100$ $\mathrm{mL}$, predominantemente ácido cólico) e elevação discreta das enzimas hepáticas, níveis de colesterol e fosfatase alcalina.$^{38}$ Ocasionalmente, há elevação discreta a moderada dos níveis de bilirrubina (2-5 mg/dL nas doentes ictéricas). Os níveis dos ácidos biliares correlacionam-se com a gravidade do prurido. Devem ser excluídas outras causas de icterícia (hepatites virais, fármacos hepatotóxicos) e prurido secundário a outras doenças cutâneas.

Tratamento - Os objectivos do tratamento são a melhoria da sintomatologia e das alterações bioquímicas maternas, assim como melhorar o prognóstico fetal. O tratamento com emolientes, antipruriginosos tópicos e anti-histamínicos orais é pouco útil.

O ácido ursodesoxicólico é o tratamento de primeira linha e pode diminuir os riscos fetais (stress fetal, baixo peso à nascença e parto prematuro). ${ }^{39}$ Este fármaco diminui os níveis de ácidos biliares no sangue do cordão umbilical, colostro e líquido amniótico. As doses recomendadas são 15 $\mathrm{mg} / \mathrm{Kg} / \mathrm{dia}$ ou, independentemente do peso corporal, $1 \mathrm{~g} /$ dia em dose única ou dividido em 2-3 doses, até ao parto. Geralmente é bem tolerado, sendo apenas referido, por vezes, diarreia ligeira. O seu uso no entanto não está aprovado durante a gravidez, sendo uma terapêutica 'off-label'.

A colestiramina (até $18 \mathrm{~g} / \mathrm{dia}$ ) pode ser eficaz na CIHG ligeira a moderada, embora demore alguns dias até se obter o controlo do prurido. ${ }^{37}$ Além do mais, a colestiramina não tem efeito nos níveis séricos dos ácidos biliares nem nas outras alterações bioquímicas. Ainda, é potencialmente prejudicial ao contribuir para a má-absorção da vitamina K, com possíveis complicações hemorrágicas. ${ }^{40}$

É recomendável uma abordagem multidisciplinar desta patologia, em que além do tratamento com ácido ursodesoxicólico, deve efectuar-se vigilância obstétrica apertada (cardiotocografia fetal semanal a partir da $34^{a}$ semana de gestação) e indução do parto assim que for atingida a maturidade pulmonar fetal ( $36-37^{\mathrm{a}}$ semanas)..$^{41}$

Complicações - Na maioria das vezes, o prognóstico materno é bom, com resolução espontânea do quadro após o parto. No entanto, nos casos acompanhados de icterícia ou deficiência de vitamina $\mathrm{K}$, há risco aumentado de hemorragia durante o parto e no período pós-parto, assim como risco aumentado de cálculos biliares. Pode ocorrer recidiva da CIHG com a toma de anticonceptivos orais, par-

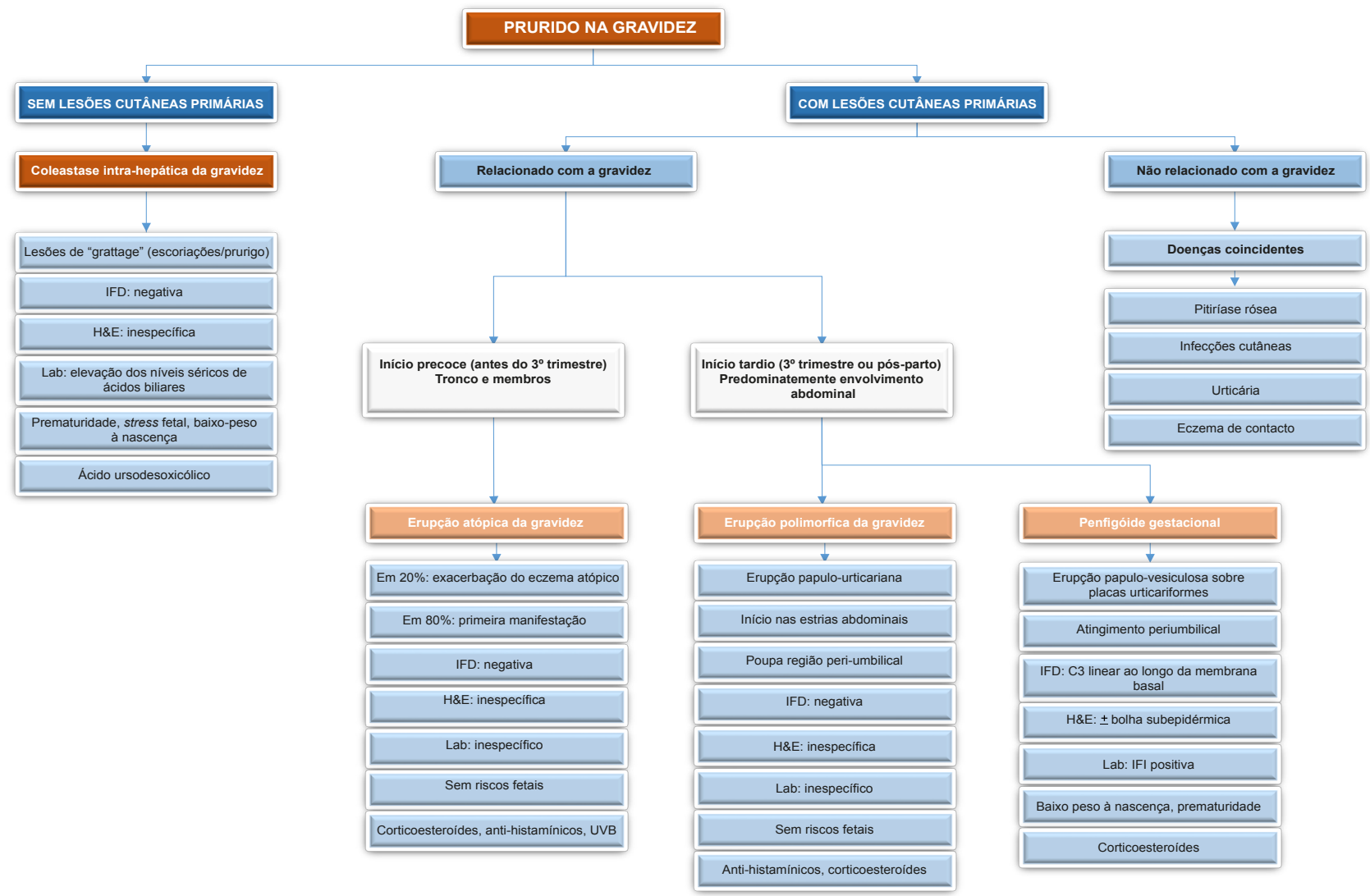

Figura 3 - Algoritmo de abordagem do prurido na gravidez. Adaptado de Ambros-Rudolph C. ${ }^{11}$ 
ticularmente se tiverem elevado teor de estrogénios.

O principal motivo de alerta nesta patologia são os potenciais riscos fetais, provavelmente associados com a acumulação dos sais biliares no compartimento fetal. A diminuição da eliminação fetal destes ácidos biliares tóxicos pode causar vasoconstrição das veias coriónicas da placenta e aumento da contractilidade uterina, podendo ser a causa do parto pré-termo em $40 \%$ dos casos. Há ainda risco de stress fetal (30\%) e nado-morto (até $4 \%$ ), devido a anoxia placentária e depressão cardíaca, sobretudo nos casos com altas concentrações de ácidos biliares. ${ }^{35,42}$

O risco de complicações fetais graves impõe uma vigilância fetal apertada, apesar de permanecer por esclarecer se os parâmetros clínicos ou laboratoriais são preditivos de morte intra-uterina. ${ }^{43}$

Diagnóstico Diferencial - Apesar de muitas vezes o prurido ser o principal sintoma das dermatoses específicas da gravidez, também pode ocorrer associado a outras dermatoses que ocorrem por coincidência durante a gravidez (p.e., pitiríase rósea, infecções cutâneas, urticária, ecze$\mathrm{ma})$.

O primeiro passo é excluir essas situações. Depois, é importante abordar as dermatoses específicas da gravidez (Fig. 2). A erupção polimorfa da gravidez ocorre mais frequentemente nas primíparas e nas gestações gemelares. Uma história de gestações anteriores afectadas com lesões cutâneas semelhantes é típica nas doentes com colestase intra-hepática da gravidez. O penfigóide gestacional e a colestase intra-hepática da gravidez surgem no final da gestação, ao passo que a erupção atópica da gravidez inicia-se significativamente mais cedo, com início antes do terceiro trimestre em $75 \%$ dos casos.

O envolvimento abdominal é característico do penfigói- de gestacional e da erupção polimorfa da gravidez. O atingimento predominante dos membros ocorre na colestase intra-hepática da gravidez, enquanto na erupção atópica da gravidez ocorre igual envolvimento dos membros e tronco. A colestase intra-hepática da gravidez é a única dermatose em que o prurido é a forma de manifestação da doença, seguido exclusivamente pelo aparecimento de lesões secundárias. $\mathrm{O}$ algoritmo apresentado na Fig. 3 foi desenvolvido para facilitar o diagnóstico diferencial das várias dermatoses pruriginosas da gravidez. ${ }^{11}$

\section{CONCLUSÃO}

Durante a gravidez, as alterações imunológicas, endócrinas, metabólicas e vasculares tornam a mulher mais susceptível a manifestações cutâneas que podem ser patológicas. Nos últimos anos foram revistas as classificações prévias e apresentadas alternativas, as quais agrupam entidades com um certo overlap sob a mesma designação (erupção atópica da gravidez). No entanto, são necessários estudos prospectivos de maiores dimensões para esclarecer a etipatogénese e estabelecer normas de orientação do tratamento das dermatoses da gravidez, visando optimizar o prognóstico materno-fetal.

\section{CONFLITOS DE INTERESSE}

Os autores declaram a inexistência de conflitos de interesse.

\section{FONTES DE FINANCIAMENTO}

Os autores declaram a inexistência de fontes de financiamento externos. Tema previamente apresentado oralmente no XIX Congresso IberoLatino Americano de Dermatologia, em Sevilha, no dia 18 Setembro de 2012.

\section{REFERÊNCIAS}

1. Ambros-Rudolph CM, Mullegger RR, Vaughan-Jones SA, Kerl H, Black MM. The specific dermatoses of pregnancy revisited and reclassified: results of a retrospective two-center study on 505 pregnant patients. J Am Acad Dermatol. 2006;54:395-404.

2. Semkova K, Black MM. Pemphigoid gestationis: Current insights into pathogenesis and treatment. Eur J Obst Gynecol Reprod Biol. 2009;145:138-44.

3. Jenkins RE, Hern S, Black MM. Clinical features and management of 87 patients with pemphigoid gestationis. Clin Exp Dermatol. 1999; 24:2559.

4. Kroumpouzos G, Cohen LM. Dermatoses of pregnancy. J Am Acad Dermatol. 2001;45:1-19.

5. Amato L, Mei S, Gallerani I, Moretti S, Fabbri P. A case of chronic herpes gestationis: persistent disease or conversion to bullous pemphigoid? J Am Acad Dermatol. 2003;49:302-7.

6. Hern S, Harman K, Bhogal BS, Black MM. A severe persistent case of pemphigoid gestationis treated with intravenous immunoglobulins and cyclosporin. Clin Exp Dermatol. 1998;23:185-8.

7. Holmes RC, Williamson DM, Black MM. Herpes gestationis persisting for 12 years postpartum. Arch Dermatol. 1986;122:375-6.

8. Rodrigues CS, Filipe P, Solana MM, Soares de Almeida L, Cirne de Castro J, Gomes MM. Persistent herpes gestationis treated with high-dose intravenous immunoglobulin. Acta Derm Venereol. 2007;87:184-6.

9. Holmes RC, Black MM, Jurecka W, Dann J, James DC, Timlin D, et al. Clues to the etiology and pathogenesis of herpes gestationis. $\mathrm{Br} \mathrm{J}$ Dermatol. 1983;109:131-9.

10. Engineer L, Bhol K, Ahmed AR. Pemphigoid gestationis: a review. Am J Obstet Gynecol. 2000;183:483-91.

11. Ambros-Rudolph CM. Dermatoses of pregnancy - clues to diagnosis, fetal risk and therapy. Ann Dermatol. 2011;23:265-75.

12. Shornick JK, Black MM. Fetal risks in herpes gestationis. J Am Acad Dermatol. 1992;26:63-8.

13. Huilaja L, Hurskainen T, Autio-Harmainen H, Hofmann SC, Sormunen $\mathrm{R}$, Räsänen $\mathrm{J}$, et al. Pemphigoid gestationis autoantigen, transmembrane collagen $\mathrm{XVII}$, promotes the migration of cytotrophoblastic cells of placenta and is a structural component of fetal membranes. Matrix Biol. 2008;27:190-200.

14. Karna P, Broecker AH. Neonatal herpes gestationis. J Pediatr. 1991;119: 299-301.

15. Lawley TJ, Hertz KC, Wade TR, Ackerman AB, Katz SI. Pruritic urticarial papules and plaques of pregnancy. JAMA. 1979;241:1696-9.

16. Ambros-Rudolph CM, Al-Fares S, Vaughan-Jones SA, Müllegger RR, Kerl H, Black MM. Polymorphic eruption of pregnancy: clinicopathology and potential trigger factors in 181 patients. Br J Dermatol. 2006;154:5460.

17. Kroumpouzos G, Cohen LM. Specific dermatoses of pregnancy: an evidence-based systematic review. Am J Obstet Gynecol. 2003;188:108392.

18. Cohen LM, Capeless EL, Krusinski PA, Maloney ME. Pruritic urticarial papules and plaques of pregnancy and its relationship to maternal-fetal weight gain and twin pregnancy. Arch Dermatol. 1989;125:1534-6.

19. Ohel I, Levy A, Silverstein T, Holcberg G, Sheiner E. Pregnancy outcome of patients with pruritic urticarial papules and plaques of pregnancy. J Matern Fetal Neonatal Med. 2006;19:305-8.

20. Elling SV, McKenna P, Powell FC. Pruritic urticarial papules and plaques of pregnancy in twin and triplet pregnancies. J Eur Acad Dermatol Ve- 
nereol. 2000:14:378- 81.

21. Pauwels C, Bucaille-Fleury L, Recanati G. Pruritic urticarial papules and plaques of pregnancy: relationship to maternal weight gain and twin or triplet pregnancies. Arch Dermatol. 1994;130:801-2.

22. Regnier S, Fermand V, Levy P, Uzan S, Aractingi S. A case-control study of polymorphic eruption of pregnancy. J Am Acad Dermatol. 2008;58:63-

23. Holmes RC, Jurecka W, Black MM. A comparative histopathologic study of polymorphic eruption of pregnancy and herpes gestationis. Clin Exp Dermatol. 1983;8:523-9.

24. Buhimschi CS, Weiner CP. Medications in pregnancy and lactation: part 2. Drugs with minimal or unknown human teratogenic effect. Obstet Gynecol. 2009;113:417-32.

25. Weber-Schoendorfer C, Schaefer C. The safety of cetirizine during pregnancy. A prospective observational cohort study. Reprod Toxicol. 2008;26:19-23.

26. Gabbe SG. Drug therapy in autoimmune disease. Clin Obstet Gynecol. 1987;26:635-41.

27. Warshauer E, Mercurio M. Update on dermatoses of pregnancy. Int $\mathrm{J}$ Dermatol. 2013;52:6-13.

28. Roth MM. Atopic eruption of pregnancy: a new disease concept. J Eur Acad Dermatol Venereol. 2009;23:1466-7.

29. Cho S, Kim HJ, Oh SH, Park CO, Jung JY, Lee KH. The influence of pregnancy and menstruation on the deterioration of atopic dermatitis symptoms. Ann Dematol. 2010;22:180-5.

30. Ingber A. Atopic eruption of pregnancy. J Eur Acad Dermatol Venereol. 2010;24:984

31. Bos JD. Reappraisal of dermatoses of pregnancy. Lancet. 1999;354:1140-2

32. Vaughan Jones SA, Hern S, Nelson-Piercy C, Seed PT, Black MM. A prospective study of 200 women with dermatoses of pregnancy correlating clinical findings with hormonal and immunopathological profiles. $\mathrm{Br} \mathrm{J}$
Dermatol. 1999;41:71-81

33. Kroumpouzos G, Cohen LM. Pruritic folliculitis of pregnancy. J Am Acad Dermatol. 2000;43:32-4

34. Reed J, George S. Pruritic folliculitis of pregnancy treated with narrowband (TL-01) ultraviolet B phototherapy. Br J Dermatol. 1999;141:177-9.

35. Geenes V, Williamson C. Intrahepatic cholestasis of pregnancy. World J Gastroenterol. 2009;15:2049-66.

36. Kroumpouzos G. Intrahepatic cholestasis of pregnancy: what's new. J. Eur. Acad Dermatol Venereol. 2002;16:316-8.

37. Ropponen A, Sund R, Riikonen S, Ylikorkala O, Aittomäki K. Intrahepatic cholestasis of pregnancy as an indicator of liver and biliary diseases: a population-based study. Hepatology. 2006;43:723-8.

38. Reyes H, Báez ME, González MC, Hernández I, Palma J, Ribalta J, et al. Selenium, zinc and copper plasma levels in intrahepatic cholestasis of pregnancy, in normal pregnancies and in healthy individuals, in Chile. J Hepatol. 2000;32:542-9.

39. Laifer SA, Stiller RJ, Siddiqui DS, Dunston-Boone G, Whetham JC. Ursodeoxycholic acid for the treatment of intrahepatic cholestasis of pregnancy. J Matern Fetal Med. 2001;10:131-5.

40. Sadler LC, Lane M, North R. Severe fetal intracranial haemorrhage during treatment with cholestyramine for intrahepatic cholestasis of pregnancy. Br J Obstet Gynaecol. 1995;102:169-70.

41. Roncaglia N, Arreghini A, Locatelli A, Bellini P, Andreotti C, Ghidini A Obstetric cholestasis: outcome with active management. Eur J Obstet Gynecol Reprod Biol. 2002;100:167-70.

42. Kondrackiene J, Kupcinskas L. Intrahepatic cholestasis of pregnancy current achievements and unsolved problems. World J Gastroenterol. 2008;14:5781-8.

43. Saleh MM, Abdo KR. Intrahepatic cholestasis of pregnancy: review of the literature and evaluation of current evidence. J Womens Health. 2007;16:833-41. 